\title{
An Analysis Of 2008 Global Crisis Through Comparative Economic Performance On The Commonwealth Of Independent States And Baltic States
}

\author{
Savaş Erdoğan, Selçuk Üniversitesi \\ Ahmet Ay, Selçuk Üniversitesi \\ Mustafa Gerçeker, Selçuk Üniversitesi
}

\begin{abstract}
In this research, EU members Baltic States (Estonia, Latvia and Lithuania) and Commonwealth of Independent States (CIS) countries Azerbaijan, Kazakhstan and Turkmenistan analyasis comperatively with the TOPSIS Method during 2001-2009 years. This research prove that 2008 and 2009 years of all countries, as expressed global financial crises period, economic performance decreased very sharply.
\end{abstract}

JEL Codes: C30 - R10

\section{Giriş}

1992 yılında Sovyet Sosyalist Cumhuriyet Birliği'nin (SSCB) dağılmasında sonra, çok sayıda ülke kendi bağımsızlığını ilan etmiştir. Bu bağımsızlık sonrası ülkeler SSCB'nin etkisinden bir an önce kurtulmak için dünya ekonomisi ile entegre olma eğilimi içerisine girmişlerdir. Ülkelerin dünya ülkeleri ile bütünleşme çabası içerisinde yapmış oldukları politikalar nedeniyle bu ülkeler geçiş ekonomileri olarak adlandırılmaktadır. Geçiş ekonomileri olarak ifade edilen ülkeler, Doğu Avrupa Bloğu ile Orta Asya ve Kafkas olmak üzere farklı bölgelere ayrılmaktadır. Bu çalışmada, doğu bloğu ülkeler içerisinde yer alan Baltık Ülkeleri (Estonya, Letonya, Litvanya) ile Bağımsız Devletler Topluluğu olarak ifade edilen Azerbaycan, Kazakistan ve Türkmenistan ekonomilerinin 2001-2009 yılları arasındaki ekonomik performansları Topsis metodu yardımı ile test edilmiştir.

\section{Baltık ve BDT Ülkelerinin Ekonomik Değerlendirmesi}

Gerek Baltık gerekse Bağımsız Devletler Topluluğu (BDT) olarak ifade edilen ve SSCB'den ayrılan ülkelerin, bağımsızlıklarını ilan ettikleri ilk yıllar haricinde dünya ekonomisi ile entegre olma süreçleri kolay olmuştur. Özellikle bu ülkelerin gayri safi milli hasılaları (GSMH), dış ticaret hacimleri ve doğrudan yabancı sermaye yatırımlarındaki hızlı artışlar 2000'li yıllarda belirgin hale gelmiştir.

Çalışmamızdaki analize konu olan Baltık ülkeleri Estonya, Letonya ve Litvanya'nın Avrupa Birliğine giriş yılı olan 2004 yılından itibaren ekonomik gelişmeleri hız kazanmıştır. Bu ülkelerin 2000 ve 2008 yılları kıyaslandığında yaklaşık olarak GSMH'ları 4,5 kat artış göstermiştir. Bu ülkelerin artış hızları aynı iken, grafiksel olarak meydana gelen artış trendlerde benzerlik göstermektedir (Grafik 1). 2009 kriz yılında ise belirgin bir şekilde ülke ekonomileri daralma eğilimi göstermiştir. 


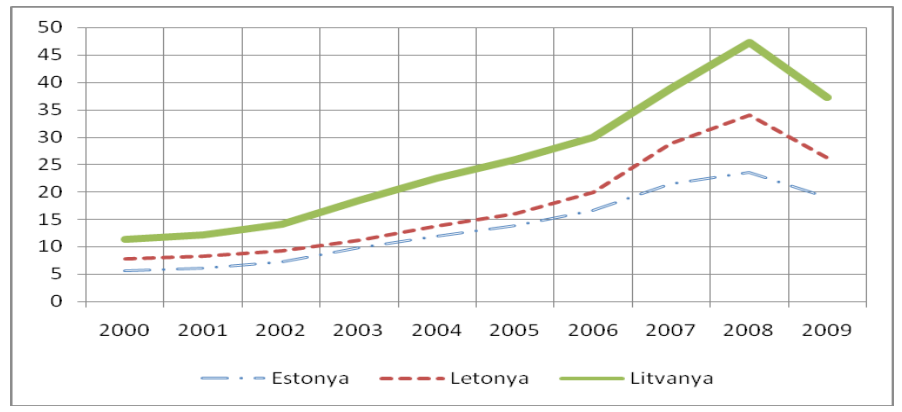

\section{Grafik 1: Baltık Ülkelerinin 2000-2009 Yılları Arasındaki GSMH Değerleri}

Bağımsız Devletler Topluluğu ülkelerinden Azerbaycan, Kazakistan ve Türkmenistan ise sahip oldukları doğalgaz ve petrol rezervleri sayesinde son dönemlerde dünya ülkeleri ile daha kolay entegre olmuşlardır. Bu durum, ülkelerin daha hzılı büyümesine olanak sağlamıştır. Şöyleki 2000 yılı ile 2008 yılı karşılaştırıldığında bu ülkelerin GSMH'sındaki cari düzeydeki artış şaşırtıcı derecede hızlı olmuştur. Bu dönemler arasında GSMH; Azerbaycan'da 9, Kazakistan'da 8 ve Türkmenistan'da ise 5 kat artış göstermiştir. Özellikle Kazakistan ve Azerbaycan ekonomisindeki GSMH artışı değer olarak göze çarpmaktadır. Azerbaycan'ın 2000 yılı GSMH's1 5 milyar dolar civarında iken, 2008 yılında 46 milyar dolara, Kazakistan'ın 2000 yılı GSMH'sı yaklaşık 18 milyar dolar iken 2008 yılında 133 milyar dolara yükselmiştir (Garfik 2).

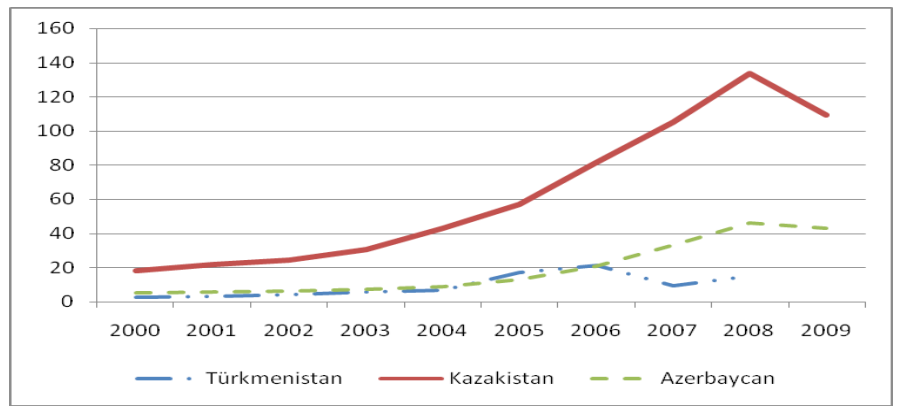

Grafik 2: BDT Ülkelerinin 2000-2009 Yılları Arasındaki GSMH Değerleri

$\mathrm{Bu}$ ülkelerin dışa açılma durumları incelendiğinde, Baltık ülkelerinin dış ticaret hacminin 2000 yılında ekonomik büyüme ile birlikte artış gösterdiği görülmektedir. Ama bu ülkelerin ortak noktaları bu dönemler arasında sürekli dış ticaret açığı vermeleri olmuştur. Ayrıca söz konusu ülkelerin 2004 yılında AB üyesi olması, doğrudan yabancı sermaye akımlarını da, 2004 yılından itibaren olumlu yönde etkilemiş ve belirgin bir artış söz konusu olmuştur.



Grafik 3: Baltık ülkelerinin Dış Ticaret Hacmi ve Doğrudan Yabancı Sermaye Hareketleri 
BDT ülkeleri, sahip oldukları petrol ve doğalgaz rezervleri ile 2000'li yıllarda ihracatları ve ithalatları daha fazla artış göstermiştir. Ama bu artışlarda ihracatın artış hızı ithalatın artış hızından daha fazla olmuş ve bunun sonucunda BDT ülkeleri söz konusu dönem içerisinde sürekli dış ticaret fazlası elde etmişlerdir. Doğrudan yabancı sermaye hareketlerine bakıldığında, özellikle Kazakistan ekonomisinde ciddi derecede bir artıș söz konusu olmuștur. Azerbaycan ekonomisinde 2006 ve 2007 yılı için yabancı sermaye çıkışları gerçekleşmiştir.

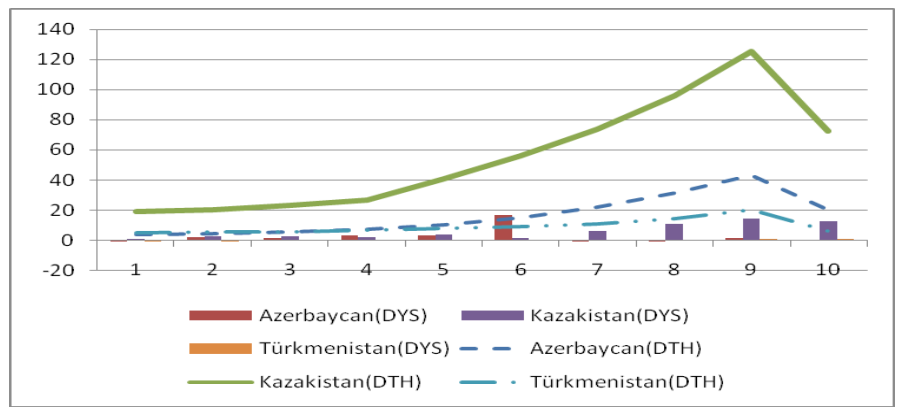

Grafik 4: BDT Ülkelerinin Dış Ticaret Hacmi ve Doğrudan Yabancı Sermaye Hareketleri (Milyar Dolar)

\section{Veriler ve Metodolojik Analiz}

Çalışmada kullanılan 2001 - 2009 yıllarına ait "Ekonomik Büyüme (EG), Enflasyon oranı (ENF), İhracat (EXP), İthalat (IMP) ve Doğrudan Yabancı Sermaye Yatırımı (FDI)" verileri, dünya bankasının "databank.worldbank.org" veri tabanından temin edilmiş olup, 2009 verileri ise, unctad.org internet sitesinden "World Investment Report 2010" veri tabanı ile çalışmada adı geçen ülkelerin merkez bankalarının internet sitelerinden temin edilmiştir. Ülkelerin ekonomik yapılarının yani büyüklüklerinin farklı olması nedeni ile çalışmada kullanılan veriler yıllar itibari ile yüzdesel değişmeler alınarak yapılmıştır.

Çalışmada, ülkelerin ekonomik performansını ölçmek için kullanılan performans denklemi (P) veriler için kullanılan belirli bir ağırlık ölçütü (w) ile elde edilen bir fonksiyondur. Bu fonksiyon (i) belli bir yılı ifade etmek üzere;

$$
\mathrm{P}(\mathrm{i})=\mathrm{w}_{1} \mathrm{EG}+\mathrm{w}_{2} \mathrm{ENF}+\mathrm{w}_{3} \mathrm{EXP}+\mathrm{w}_{4} \mathrm{IMP}+\mathrm{w}_{5} \mathrm{FDI} \quad(\mathrm{i}=1,2,3,4
$$

şeklinde tanımlanmaktadır.

Ülkenin ekonomik performans kriterini ölçmek için çok kriterli karar verme yöntemlerinden TOPSISS metodu kullanılmıştır. Baltık ve BDT Ülkelerinin ekonomik performansının ölçülmesi için kullanılan bu yöntem; Eleren ve Karagül'ün 2008 yılında yapmış olduğu Türkiye'nin ekonomik performansını araştıran çalışmasından yola çıkılarak yapılmıştır.

$\mathrm{Bu}$ yöntemle, beş değişkene dayalı tek bir performans puanının hesaplanması ve buna göre performans büyüklüklerinin sıralanabilmesi amaçlanmıștır. Bu yöntem uygulanırken kullanılan veriler, ülke ekonomilerinin görece büyüklükleri birbirinden farklı olduğu için cari değerler üzerinden ele alınmayıp, yıllar itibari ile yüzdesel değișimler olarak kullanılmıştır. Ayrıca bu yöntemin uygulanması durumunda, ülkelerin bu değişkenlere verdiği tepkilerin aynı olduğu, yani ağırlandırılmış derecelerin 1 olduğu varsayılmıştır.

\subsection{Topsis Yöntemi}

Topsis Yöntemi, Hwang ve Yoon tarafindan çok kriterli karar verme tekniği olarak geliştirilmiştir (Shyjith vd. 2008). Yöntemin temeli, pozitif ideal çözüme en yakın mesafe ve negatif ideal çözüme en uzak mesafedeki alternatifi seçmeye dayanmaktadır. Topsis yönteminin yapılış aşamaları aşağıdaki şekildedir (www. deu.edu.tr/userweb/k.yaralioglu/dosyalar/TOPSIS_yontemi.doc ). 
I - Karar matrisinin oluşturulması (A).

$A=\left\lfloor a_{i j}\right\rfloor_{m x n}$ şeklinde verilen karar matrisinde m karar noktası sayısını, $\mathrm{n}$ ise değerlendirme faktörü sayısını ifade etmek üzere, oluşturulan A matrisi i alternatifinin j kriterine göre gerçek değerini ifade etmektedir.

II - Standart karar matrisinin oluşturulması (R ).

Standart karar matrisi, A matrisinden yola çıkarak ve aşağıdaki formül kullanılarak hesaplanır.

$$
R_{i j}=\frac{a_{i j}}{\sqrt{\sum_{k=1}^{m} a_{k j}^{2}}}
$$

III - Ağırlıklı standart karar matrisin oluşturulması (V).

Değerlendirme faktörüne ilişkin ağırlık dereceleri (w) belirlenir. Bu değerler ile V matrisi $\mathrm{V}=\mathrm{W}_{\mathrm{i}} \cdot \mathrm{R}_{\mathrm{ij}}$ matrisi oluşturulur.

IV- Ağırlıklı standart karar verme matrisinden yola çıkarak, ideal $\mathrm{A}^{+}$ve negatif ideal $\mathrm{A}^{-}$ çözümleri oluşturulur. Pozitif ideal çözüm, ağırlıklı standart karar matrisinin en iyi performans değerinden oluşurken negatif ideal çözüm ise en kötü değerlerden oluşur. Bu en iyi ve en kötü değerler kullanılarak $\mathrm{J}^{+}$maksimizasyon ve $\mathrm{J}^{-}$minimizasyon değeri elde edilmektedir.

$$
\begin{aligned}
& A^{+}=\left\{\left(\max v_{i j} \mid j \in J\right\}\right. \\
& A^{-}=\left\{\left(\min v_{i j} \mid j \in J\right\}\right.
\end{aligned}
$$

V - J alternatif ideal çözümden uzaklığı ideal ayırım $\mathrm{S}^{+}$, negatif ideal çözümden uzaklığ negatif ideal ayırımı $\mathrm{S}^{`}$ sırası ile aşağıdaki formüllerden faydalanarak yapılır.

$$
S^{+}=\sqrt{\sum_{j=1}^{n}\left(v_{i j}-v^{+}{ }_{j}\right)^{2}} \quad \text { ve } \quad S^{-}=\sqrt{\sum_{j=1}^{n}\left(v_{i j}-v^{-}{ }_{j}\right)^{2}}
$$

VI - pozitif ve negatif ideal ayırımlardan yola çıkarak, $C=\frac{S^{-}}{S^{+}+S^{-}}$formülü yardımı ile ideal çözüme göreli yakınlık hesaplanır. C değeri 0 ve 1 dâhil olmak üzere bu aralıklarda yer alır. C değeri bire yakınlaşması pozitif ideal çözüme, sıfıra yakınlaşması negatif ideal çözüme yakınlaştığını gösterir. Böylece bire yakın olan değer daha iyi performansı ifade eder.

\subsection{Bulgular}

Estonya, Letonya, Litvanya (Batlık ülkeleri) ile Azerbaycan, Kazakistan ve Türkmenistan (BDT) ülkelerine ait 2001 - 2009 yıllarına ait ekonomik performans, aşağıdaki denklem yardımı ile ifade edilmektedir.

$$
\mathrm{P}(\mathrm{i})=\mathrm{w}_{1} \mathrm{EG}+\mathrm{w}_{2} \mathrm{ENF}+\mathrm{w}_{3} \mathrm{EXP}+\mathrm{w}_{4} \mathrm{IMP}+\mathrm{w}_{5} \mathrm{FDI} \quad(\mathrm{i}=1,2,3,4
$$

Buna göre, denklemi oluşturan performans değişkenleri Ekonomik Büyüme (EG), Enflasyon Oranı (ENF), İhracat (EXP), İthalat (IMP) ve Doğrudan Yabancı Sermaye Yatırımı (FDI) olarak tanımlanmaktadır. Bu verilere ait karar matrisi verilerin değerleri ile oluşturulur.

$\mathrm{Bu}$ karar matrisinden yola çıkarak, standart karar matrisi oluşturulur. Bu matriste ağırlık derecesini ifade eden $\mathrm{w}$ değeri 1 olarak alınmıştır.

Faktör değerlerden (sütunlardan) yola çıkarak performansı en iyi olan (yani en yüksek) değer ve en kötü olan (yani en düşük) değerler seçilir. Bu seçim yapılırken ekonomik performansta yüksek ve düşük değerlerin iyi ya da kötü olmasına bakılır. Maksimum ve minimum değerler ile pozitif ve negatif ideal çözümden uzaklığı ifade eden S matrisi oluşturulur. İdeal çözümün 
ifade edildiği ülkelere ait performans değerleri grafikleri aşağıda gösterilmiştir.

$\mathrm{Bu}$ grafiklerde, ülkelerin yıllar itibari ile ekonomik performans değerleri ve 2001-2009 dönemine ait ortalama performans değeri gösterilmiştir. Ülkelerin tek tek analiz edilmesi durumunda, Türkmenistan 2002, 2005 ve 2006 yıllarında ortalama değerden daha yüksek bir performans göstermiştir. Kazakistan ekonomisi ise, 2001, 2004, 2006, 2007 ve 2008 yıllarında ortalama değerden daha yüksek veya aynı derecede performans göstermiştir. Azerbaycan ekonomisi ise, 2001,2002, 20042005 ve 2007 yıllarında ortalama değere eş değer ya da daha yüksek performans göstermiştir. Baltık ülkelerinde ise, özellikle Letonya ekonomisi dikkat çekmektedir. Bu ülke, kriz dönemleri haricinde $(2008$, 2009) ortalama değerin üzerinde seyretmiştir. Estonya ülkesi ise, 2003, 2005 ve 2007 yıllarında ortalama değerin üzerine çıkmıştır. Litvanya ekonomisinin ekonomik performansı ise, 2004 yılı haricinde genellikle ortalama değerde seyretmiştir. Bütün bu ülkelere bakıldığında, küresel mali kriz dönemlerini ifade eden 2008 ve 2009 yıllarında ekonomik performanslarının düştüğ̈̈ görülmektedir. Bu demek oluyor ki, küresel mali kriz ile ülkelere ait bu değişkenler ele alındığında söz konusu ekonomilerin geçmiş dönemlere göre daralma gösterdiği sonucuna ulaşılmaktadır.

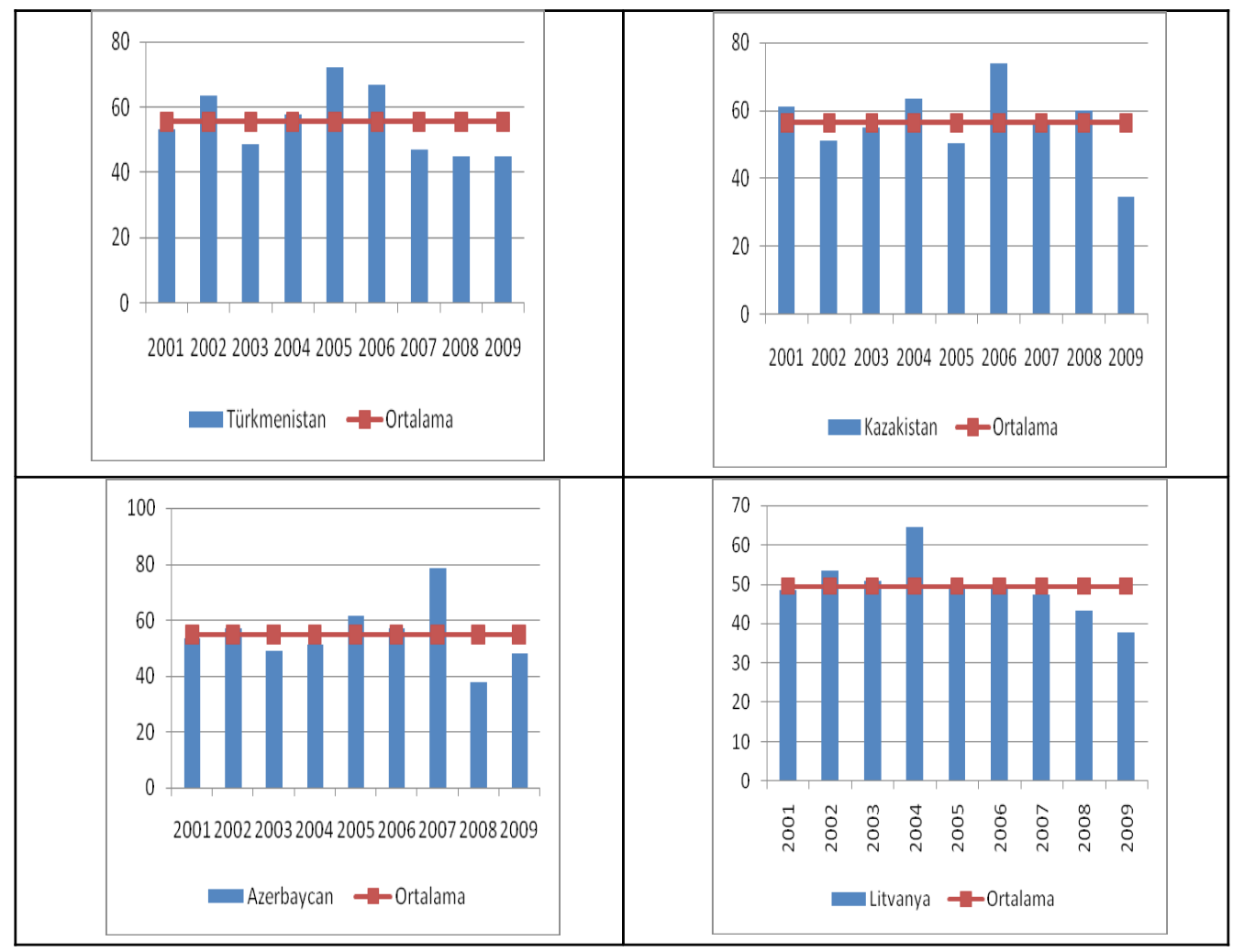




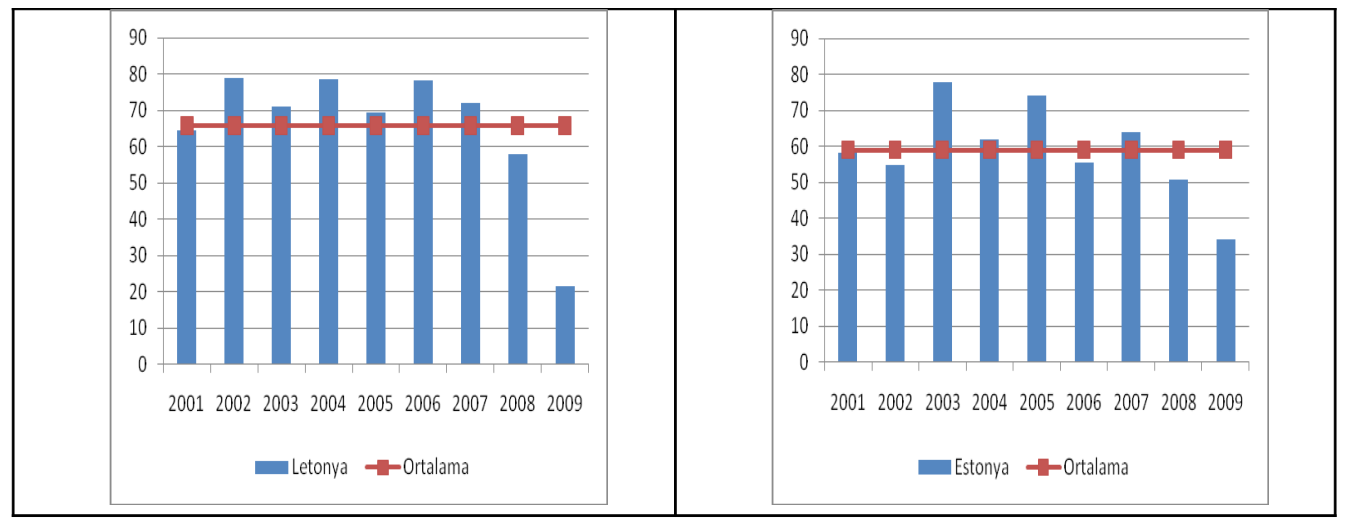

Grafik 5: İdeal Çözümden Uzakliğı Gösteren Matrise Ait Grafikler ve Ortalama Performans Değerleri

Ülkelere ait ekonomik performanslar beraberce ele alındığında, aşağıdaki tablo ortaya çıkmaktadır. Grafiğe göre, genellikle BDT ülkelerinden Kazakistan ve Azerbeycan'ın Baltık Ülkelerinde ise Letonya ve Estonya'nın ekonomik performansları dikkat çekmektedir. Ülkelere ait ekonomik performanslar mali kriz döneminde düşüş göstermiştir. Kriz döneminde ülkelerin performanslarının düşmesine rağmen, dışa açıklık derecesi düşük ve nispeten küçük ekonomilerin daha az zarar gördüğü görülebilmektedir. İthalat, ihracat ve doğrudan yabanc1 sermaye hareketlerinin yüksek olduğu ülkelerde ise mali kriz döneminde ekonomik performanslarının daha fazla düşüş gösterdiği gözlemlenmiştir (Grafik 6). Aşağıda histogram şeklinde ifade edilen ülkelerin yıllara göre ekonomik performans değerleri ve ülke sıralamaları ayrıntılı bir şekilde EK 1'deki dairesel grafiklerde gösterilmiştir.

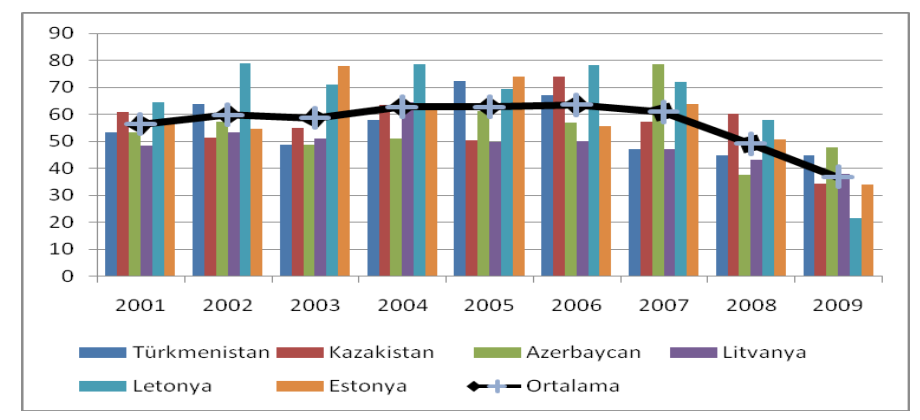

Grafik 6: Baltık ve BDT Ülkelerinin Yıllık Ortalama Değere Göre Performansları

\section{Sonuç ve Değerlendirme}

2007 yılının sonlarında başta Amerika da ortaya çıkan küresel mali kriz kısa süre içinde tüm dünya ülkelerini etkisi altına almıştır. Özellikle ABD gibi gelişmiş olan diğer ülkeleri (AB ülkeleri) bu küresel krizden önemli derecede etkilenmiştir. Dünya ekonomisine yöne veren bu ülkelerin durgunluk yaşamış olması direkt olarak diğer ülkeleri de etkilemiştir. Bu bağlamda, kürsel mali krizin çalışmamıza konu olan Baltık ve BDT ülkelerinin ekonomik performanslarını nasıl etkilediği karşılaştırmalı olarak, 2001 - 2009 yılları arasında TOPSíS yöntemi yardımı ile analiz edilmiştir. Bu yöntem ile ülkelerin yıllar itibari ile önemli ekonomik göstergeleri ele alınmıştır. Bu göstergeler ülkelerin GSMH'sı, ihracat, ithalat, enflasyon oranı 
ve doğrudan yabancı sermaye yatırım değerleri olarak inceleme yapılmıştır. Bu veriler yardımı ile yapılan analizde küresel mali krizin ülkelerin ekonomik performanslarını olumsuz yönde etkilediği ortaya çıkmıștır. Zira kriz öncesi bu ülkelerde ekonomik performans yüzde 50'lerin çok çok üzerine çıkmasına rağmen kriz yılında ise yüzde 20 ile 45 aralığında oluşmuştur. 20082009 dönemini ifade eden kriz öncesi dönem ele alındığında, ekonomik performansı yüksek olan ülkelerin kriz döneminde ise yüzdesel olarak çok düşük performanslar ortaya çıkmıștır. Analize konu olan değişkenler ele alındığında bu duruma neden olan faktör, ülkelerin dışa açıklık dereceleri ile doğrusal orantı içinde olduğunu göstermektedir.

\section{Kaynakça}

- Shyjith, vd, 2002. "Multi-criteria decision-making approach to evaluate optimum maintenance strategy in textile industry", Journal of Quality in Maintenance Engineering, Vol. 14; No. 4, pp.375 - 386.

- Alagöz, vd, 2004. "Türk Cumhuriyetleri İle İlişkilerimize Ekonomik Açıdan Bir Yaklaşım”, Selçuk Üniversitesi, Sosyal Bilimler Enstitüsü Dergisi, Sayı:12, ss:59-74

• Elener, vd, 2008. "1986 - 2006 Türkiye Ekonomisinin Performans değerlendirmesi”, Celal Bayar Üniv. Yöentim ve Ekonomi Dergisi, Cilt: 15 Sayı: 1.

- $\quad$ Altınok, vd, 2006. "Türkiye İle Türk Cumhuriyetleri Arasındaki Ticari ilişki, mevcut Durum, Geleceğe Yönelik Önlem ve Öneriler”, Ülkümüz Dergisi, Sempozyum bildirileri, Cilt:1.

- Ay, vd. 2008. Geçiş Ekonomileri. Edt.: İbrahim Örnek, Seyhan Taş ve Metin Yildırım, ss. 143 - 190, Bursa.

- World Economic Outlook October 2009. Sustaining the Recovery International Monetary Fund, http://www.imf.org/external/pubs/ft/weo/2009/02/pdf/text.pdf

- Topsis Yöntemi, 2010. www. deu.edu.tr/userweb/k.yaralioglu/dosyalar/TOPSİS_yontemi.doc

- Worldbank, 2010. http://databank.worldbank.org/ddp/home.do

- World Investment Report, 2010. http://www.unctad.org/Templates/Page.asp? intItemID $=3198 \&$ lang $=1$

- Economimc Statistic, 2010. http://www.economywatch.com/economicstatistics/country/

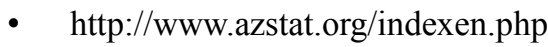

- http://www.bankofestonia.info/dynamic/itp1/itp_report_1a.jsp? reference $=545 \&$ startDay $=1 \&$ startMonth $=1 \&$ startYear $=2008 \&$ endDay $=1 \&$ endMonth $=$ $12 \&$ endYear $=2009 \&$ reference $=544 \&$ class Name $=$ EPSTAT $1 \&$ step $=11 \&$ nrOfQuarter $=0$ \& commtype $=1 \&$ lang $=$ en \&submit $=$ SHOW

- $\quad$ http://www.lb.lt/statistics/statbrowser.aspx? nccharset $=1978$ BE4D\&lang $=$ en\&orient $=$ vert\&date_type $=4 \&$ Year $0=2006 \&$ Year $1=20$ $10 \& 12 \mathrm{MONTHS}=1 \&$ group $=7234$

- $\quad$ http://www.bank.lv/LMB/LMB en.php? table level $0=19 \&$ table level $1=$ \&tables $=3$ \&lang=2 \&period- $\mathrm{f}=2009$ \&period$\mathrm{t}=2010$ \&periodiskums $=1 \&$ currency $=3$ \&bopsy lim $=0$ \&mervieniba $=2$

- $\quad$ http://www.nationalbank.kz/?docid=199 
Ek 1. Yıllar İtibari ile Ülkelerin Performans Değer Stralaması

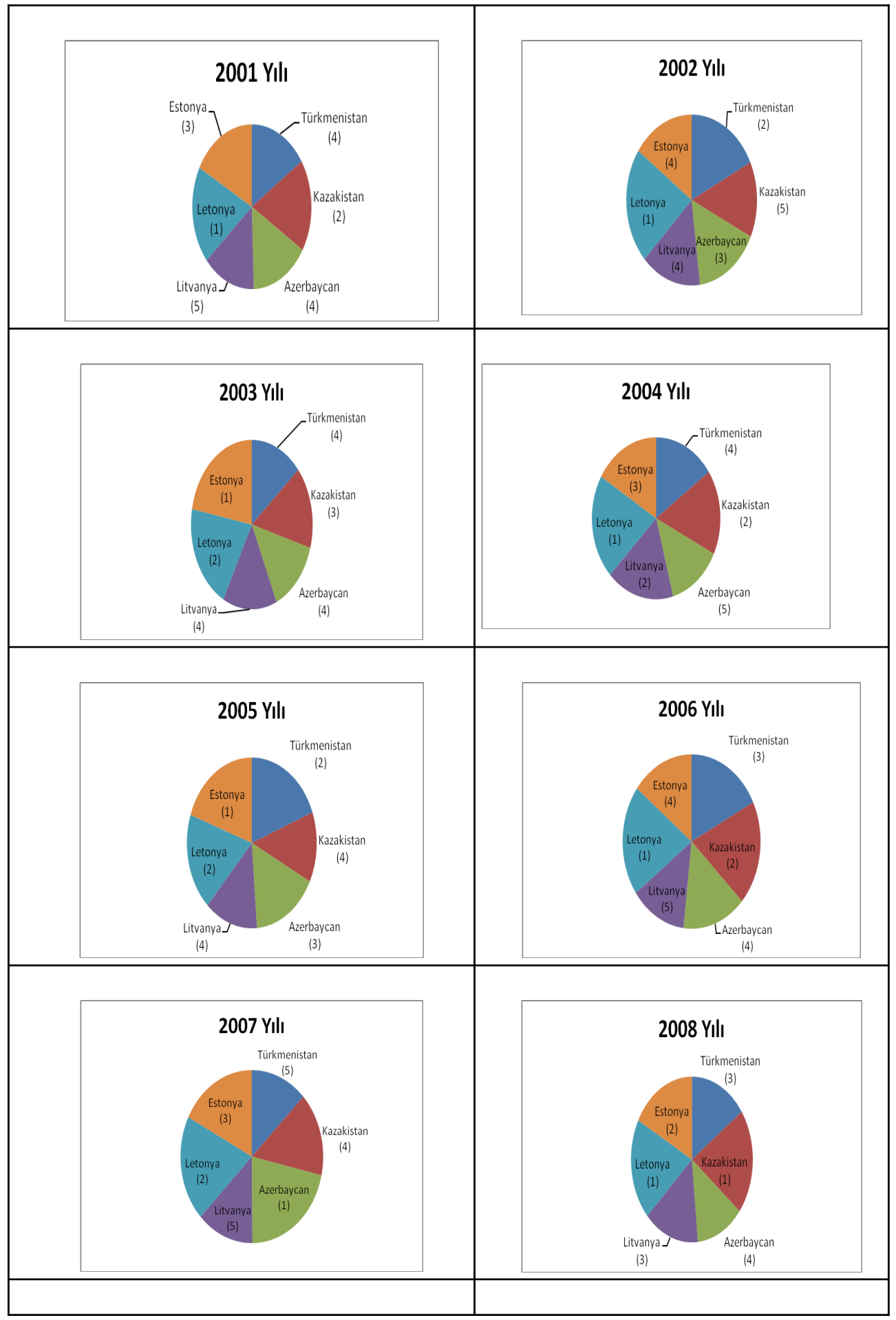




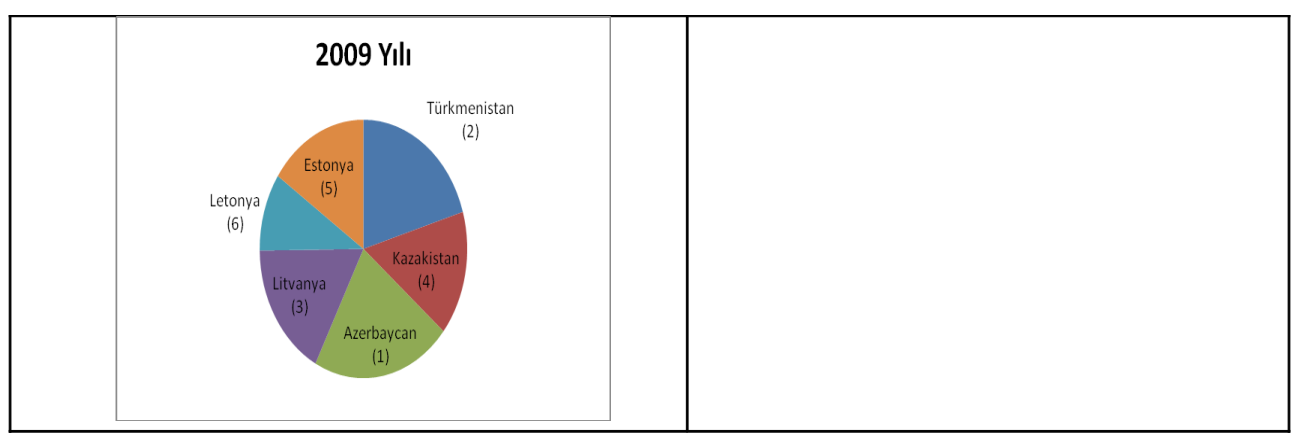

